\title{
Is there a causal effect between agricultural production and carbon dioxide emissions in Ghana?
}

\author{
Phebe Asantewaa Owusu, Samuel Asumadu-Sarkodie ${ }^{\dagger}$ \\ Sustainable Environment and Energy Systems, Middle East Technical University, Northern Cyprus Campus, Kalkanli, Guzelyurt, TRNC 99738 / Mersin \\ 10, Turkey
}

\begin{abstract}
According to FAO, "agricultural sectors are particularly exposed to the effects of climate change and increases climate variability". As a result, the study makes an attempt to answer the question: Is there a causal effect between agricultural production and carbon dioxide emissions in Ghana? By employing a time series data spanning from 1960 to 2015 using the Autoregressive Distributed Lag method. There was evidence of a long-run equilibrium relationship running from copra production, corn production, green coffee production, milled rice production, millet production, palm kernel production and sorghum production to carbon dioxide emissions. The short-run equilibrium relationship shows that, a $1 \%$ increase in copra and green coffee production will increase carbon dioxide emissions by $0.22 \%$ and $0.03 \%$, a $1 \%$ increase in millet and sorghum production will decrease carbon dioxide emissions by $0.13 \%$ and $0.11 \%$ in the short-run while a $31 \%$ of future fluctuations in carbon dioxide emissions are due to shocks in corn production. There was bidirectional causality between milled rice production and carbon dioxide emissions, millet production and carbon dioxide emissions and, sorghum production and carbon dioxide emissions; and a unidirectional causality running from corn production to carbon dioxide emissions and carbon dioxide emissions to palm kernel production.
\end{abstract}

Keywords: Agricultural production, Carbon dioxide emissions, Econometrics, Ghana, Granger-causality, Variance decomposition

\section{Introduction}

The growing urgency of climate change has become a global challenge that has propelled a global effort towards devising low-carbon industrial development, sustainable agriculture, clean and renewable energy sources and less energy-intensive economic development [1-8]. According to Food and Agriculture Organization (FAO) [9], it is perceived that global warming is as a result of burning oil and gas, however, 25-30\% of the 1.6 billion tons of global greenhouse gases released into the atmosphere is due to deforestation. Since $50 \%$ of carbon makes-up trees, the carbon dioxide emissions are released into the air during felling or burning of trees during agricultural activities. It is estimated that $80 \%$ of deforestation are due the conversion of the forest area into farmland to meet the growing food demand to feed the population [2, 9]. It is estimated that $75 \%$ of the poor and global food insecure people depend on agriculture and natural resources for their living [10]. It is noteworthy that, critical action on climate change and its impacts is crucial to promote food security and

This is an Open Access article distributed under the terms of the Creative Commons Attribution Non-Commercial License (http://creativecommons.org/licenses/by-nc/3.0/) which permits unrestricted non-commercial use, distribution, and reproduction in any medium, provided the original work is properly cited.

Copyright (C) 2017 Korean Society of Environmental Engineers eliminate hunger [4, 11, 12]. Evidence from FAO [9] shows that poor agricultural practices are high in developing countries like Africa, Southeast Asia and Latin America. According to FAO [10], "agricultural sectors are particularly exposed to the effects of climate change and increases climate variability. The impacts are already felt today and are aggravated by unsustainable practices that result in land degradation, water scarcity, biodiversity loss, and degraded ecosystem services". While there is a global response to climate change mitigation, efforts to build a sustainable agriculture and curb hunger by 2030 is at the centre of the global policy [13].

Agriculture and forestry are the backbones of Ghana's growing economy which constitutes $43 \%$ of gross domestic product (GDP), $50 \%$ of export earnings and $70 \%$ of the total employment. Because the livelihood of the local communities depends on the rich biodiversity ecosystems like agriculture, forestry and other land use, the local population are vulnerable to climate change with limited coping strategies, thus a lack of climate change adaptation options $[14,15]$.

According to United Nations Framework Convention on Climate

\footnotetext{
${ }^{\dagger}$ Corresponding author

Email: samuelsarkodie@yahoo.com

Tel: $+90-5338213422$
}

Received July 20, 2016 Accepted September 29, 2016 
Change (UNFCCC) [16], Ghana's agricultural sector requires about US\$ 334.24 million in 2020 and US\$ 336.30 million in 2050 for the impact of climate change adaptation. The investment requires research into the production of drought-tolerant crops, change in the management of crops and fisheries, management of pests and diseases, management of moisture and irrigation, fire management practices in crop production, extension and training of farmers.

Against the backdrop, it is essential to research into the causal-effect of carbon dioxide emissions and agricultural production in Ghana using modern econometric methods.

Modern econometric methods have been employed in many studies to examine the relationship between environmental pollution, energy sector and socio-economic variables in many countries [6, 17-24]. The causal relationship between GDP, electricity consumption and carbon dioxide emissions was examined in Sierra Leone using the linear regression model and variance decomposition analysis. Evidence from the study showed that the effect of fluctuations in future carbon dioxide emissions due to electricity consumption [21]. The causal relationship between GDP, electricity consumption, industrialization, population, financial development and carbon dioxide emissions was examined in Sri Lanka using the autoregressive distributed lag (ARDL) bounds test cointegration and neural network analysis. The study found evidence of a long-run equilibrium relationship running from GDP, electricity consumption, industrialization, population, financial development to carbon dioxide emissions. However, there was a bidirectional causality between from energy use and industrialization [18]. The relationship between electricity consumption, industrialization, GDP and carbon dioxide emissions was examined in Benin using the ARDL regression analysis. The study found evidence of a long-run equilibrium relationship running from electricity consumption, industrialization, GDP and carbon dioxide emissions [19]. The causal nexus between carbon dioxide emissions, technical efficiency, industrial structure and economic growth was examined in Senegal, Ghana and Morocco using the ARDL bounds test cointegration. There was evidence of multiple long-run relationships for Senegal and Ghana but a bidirectional long-run relationship for Morocco. Evidence from the variance decomposition analysis showed the effect of fluctuations in future carbon dioxide emissions due to economic growth in Morocco and Senegal while technical efficiency affects the future fluctuations in carbon dioxide emissions in Ghana [22]. The impact of population growth, energy intensity and GDP on carbon dioxide emissions in Ghana was investigated using the vector error correction model and ordinary least squares regression. Evidence from the study showed the existence of a long-run equilibrium relationship running from population growth, energy intensity and GDP to carbon dioxide emissions. In addition, there was a bidirectional causality between energy intensity and carbon dioxide emissions [25]. Both vector error correction model and ARDL regression analysis were used to estimate the relationship between population growth, energy use, GDP and carbon dioxide emissions in Ghana. Evidence from the study showed the effect of fluctuations in future carbon dioxide emissions due to energy use. There was a unidirectional causality running from carbon dioxide emissions to energy use and pop- ulation to energy use [26].

Almost all the aforementioned literature in Ghana examines the causal effect of energy intensity, socio-economic variables and environmental pollution. To the best of our knowledge, there is only one study that examines the relationship between carbon dioxide emissions and agriculture in Ghana [15]. In this study [15], both vector error correction model and ARDL regression analysis were used to estimate the relationship between agriculture and carbon dioxide emissions in Ghana. However, no consistent evidence was found between the two methods; the vector error correction model showed no causal relationship between agriculture and carbon dioxide emissions, while the ARDL regression analysis showed a causal relationship between agriculture and carbon dioxide emissions which may die over time.

The current study presents new empirical evidence on agricultural production and environmental pollution. The only study on agriculture and environmental pollution [15] failed to account for random innovations of the variables to each other in the Vector auto Regression (VAR) which is considered in the present study. The study further presents a nonparametric estimation of the strength of association between the study variables with 1,000 bootstrapped samples to examine the differences between the estimated correlation between the study variables and the bias using the bootstrapping, a resampling technique. As a contribution to literature, the study provides recent evidence of the causal effect between carbon dioxide emissions and agricultural production in Ghana by employing a data spanning from 1960 to 2015. In addition, the study increases the global debate on sustainable agriculture and climate change mitigation and its impacts from the Ghanaian perspective.

\section{Methodology}

\subsection{Data}

In order to answer the question: Is there a causal effect between agricultural production and carbon dioxide emissions in Ghana? the study employs a time series data spanning from 1960 to 2015 from Index Mundi [27] and employs the ARDL econometric approach. Eight variables are employed in the study which include; $\mathrm{CO}_{2}$-Carbon dioxide emissions (kt), COPRA-Copra Oilseed Production (1000 MT), CORN- Corn Production (1000 MT), GREENCOFFEE- Green Coffee Production (1000 60 KG BAGS), MILLEDRICE- Milled Rice Production (1000 MT), MILLET- Millet Production (1000 MT), PALMKERNEL- Palm kernel oil seed Production (1000 MT) and SORGHUM- Sorghum Production (1000 MT). The selection of variables was based on the available data on Ghana's agricultural commodity. Fig. 1 depicts the trend of the study variables. Evidence from Fig. 1 shows that all the series increase periodically.

\subsection{Model Estimation}

Fig. 2 shows the schematic presentation of the test processed employed in the study. Firstly, a descriptive analysis of the study variables is estimated to ascertain the characteristics of the 

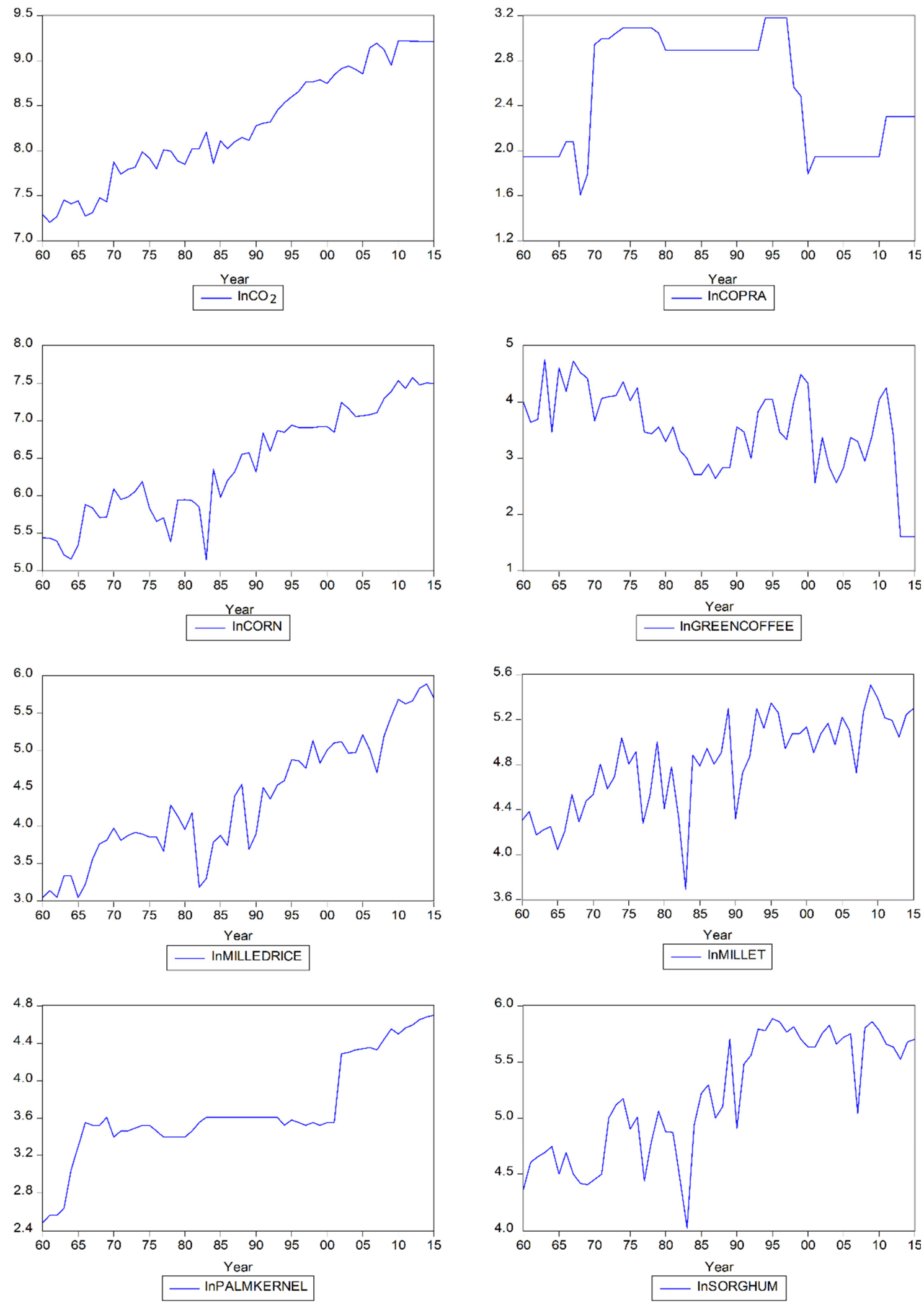

Fig. 1. Trend of study variables. 


\section{Test Processes}

(1) Descriptive Analysis: Some variables are not normally distributed, therefore logarithmic transformation is applied.

(2) Unit Root Test: Variables are integrated at I(1).

(3) Co-integration Analysis: Variables are cointegrated.

(4) Regression Analysis: Is the error correction negative and significant?, Is there a long-run and short-run caus ality?



Fig. 2. A schematic presentation of the study.

variables. The study employs Kendall's correlation coefficient estimation to examine the strength of association between two ranked variables. Secondly, a unit root test is estimated to ascertain the integration order of the study variables. Thirdly, if variables are integrated at either order zero or one, an ARDL bounds test of cointegration is estimated. Furthermore, an ARDL regression model is applied if variables are cointegrated, with a subsequent diagnostic and stability test. Finally, a Granger causality test and variance decomposition analysis are estimated to examine the direction of causality and innovation accounting of the study variables in the future.

The linear function of the relationship between carbon dioxide emissions and agricultural production can be expressed as:

$$
\begin{aligned}
L C O_{2 t}= & f\left(\text { LCOPRA }_{t}, L C O R N_{t}, L G R E E N C O F F E E_{t},\right. \\
& \text { LMILLEDRICE }, \text { LMLLET }, \text { LPALMKERNEL } L_{t} \\
& \text { LSORGHUM }_{t}
\end{aligned}
$$

The empirical specification of the proposed model is expressed as:

$$
\begin{aligned}
L_{C O}= & \beta_{0}+\beta_{1} \text { LCOPRA }_{t}+\beta_{2} \text { LCORN }_{t}+\beta_{3} \text { LGREENCOFFEE }_{t}+ \\
& \beta_{4} \text { LMILLEDRICE }_{t}+\beta_{5} \text { LMILLET }_{t}+\beta_{6} \text { LPALMKERNEL }_{T}+ \\
& \beta_{7} \text { LSORGHUM }_{T}+\varepsilon_{t}
\end{aligned}
$$

Where $\mathrm{LCO}_{2 t}$ is the logarithmic transformation of carbon dioxide emissions while $L C O P R A_{t}, L C O R N_{t}, L G R E E N C O F F E E_{t}$, $L M I L L E D R I C E_{t}, L M I L L E T_{t}, L P A L M K E R N E L_{t}$ and are the logarithmic transformation of Copra Oilseed Production, Corn Production, Green Coffee Production, Milled Rice Production, Millet Production, Palm kernel oil seed Production, and Sorghum Production in year $t, \varepsilon_{t}$ is the error term and $\beta_{0}, \beta_{1}, \beta_{2}, \beta_{3}, \beta_{4}$, $\beta_{5}, \beta_{6}$ and $\beta_{7}$ are the elasticities to be estimated (see Eq. (4)).

Following the work of Asumadu-Sarkodie and Owusu [15], Asumadu-Sarkodie and Owusu [26], Asumadu-Sarkodie and Owusu [28], the study employs the ARDL econometric approach due to its advantage over other econometric variables in small sample size. According to Pesaran and Shin [29], the ARDL model can be applied to variables in a cointegration at either I(0) or I(1). The proposed ARDL cointegration regression is expressed as:

$$
\begin{aligned}
& \triangle L C O_{2 t}=\alpha+\delta_{1} \text { LCO }_{2 t-1}+\delta_{2} \text { LCOPRA }_{t-1}+\delta_{3} \text { LCORN }_{t-1}+ \\
& \delta_{4} \text { LGREENCOFFEE }_{t-1}+\delta_{5} \text { LMLLLEDRICE }_{t-1}+ \\
& \delta_{6} \text { LMILLET }_{t-1}+\delta_{7} \text { LPALMKERNEL }_{t-1}+\delta_{8} \text { LSORGHUM }_{t-1}+ \\
& \sum_{i=1}^{p} \beta_{1} \triangle L C O_{2 t-i}+\sum_{i=0}^{p} \beta_{2} \triangle L C O P R A_{t-i}+ \\
& \sum_{i=0}^{p} \beta_{3} \triangle L C O R N_{t-i}+\sum_{i=0}^{p} \beta_{4} \triangle L G R E E N C O F F E E_{t-i}+ \\
& \sum_{i=0}^{p} \beta_{5} \triangle L M L L E D R I C E_{t-i}+\sum_{i=0}^{p} \beta_{6} \triangle \text { LMILLET }_{t-i}+ \\
& \sum_{i=0}^{p} \beta_{7} \triangle L P A L M K E R N E L_{t-i}+\sum_{i=0}^{p} \beta_{8} \triangle \text { LSORGHUM }_{t-i}+\varepsilon_{t}(3)
\end{aligned}
$$


Where $\alpha$ denotes the intercept, $p$ denotes the lag order, $\varepsilon_{t}$ denotes the error term and $\Delta$ denotes the first difference operator. The relationship between the variables is examined with F-tests based on the null hypothesis of no cointegration between $\mathrm{LCO}_{2}, \mathrm{LCOPRA}$, LCORN, LGREFNCOFFEE, LMILEDRICE, LMILET, LPALMKERNEL and LSORGHUM [ $H_{0}: \delta_{1}=\delta_{2}=\delta_{3}=\delta_{4}=\delta_{5}=\delta_{6}=\delta_{7}=\delta_{8}=0$ ], contrary to the alternative hypothesis of cointegration between $\mathrm{LCO}_{2}$, LCOPRA, LCORN, LGREENCOFFEE, LMILLEDRICE, LMILLET, LPALMKERNEL and LSORGHUM $\left[H_{1}: \delta_{1} \neq \delta_{2} \neq \delta_{3} \neq \delta_{4} \neq \delta_{5} \neq \delta_{6} \neq \delta_{7} \neq\right.$ $\left.\delta_{8} \neq 0\right]$. The estimated F-statistic is compared with the critical values of the lower and upper bounds [30]. According to Pesaran, Shin [30], the null hypothesis of no cointegration between series is rejected if the computed F-statistic goes beyond the upper bound otherwise, the null hypothesis of cointegration between series cannot be rejected if the F-statistic is lower than the critical values of the lower bound.

\subsection{Descriptive Analysis}

In Table 1, the descriptive statistical analysis of the study variables is given. Evidence from Table 1 shows that $\mathrm{CO}_{2}, \mathrm{CORN}$, GREENCOFEE, MILLEDRICE, MILLET, PALMKERNEL and SORGHUM exhibit a positive skewness while COPRA exhibits a negative skewness. Furthermore, while $\mathrm{CO}_{2}$, COPRA, CORN, MILLET and SORGHUM exhibit a platykurtic distribution, GREENCOFEE, MILLEDRICE and PALMKERNEL exhibit a leptokurtic distribution. Evidence from the Jarque-Bera test statistic shows that $\mathrm{CO}_{2}$, GREENCOFEE, MILLEDRICE and PALMKERNEL do not fit the normal distribution based on 5\% significance level. In order to have a stable variance in the ARDL model, the study applies a logarithmic transformation to the study variables.

As part of the descriptive statistical analysis, the study further employs Kendall's Tau_b to estimate the non-parametric measure of strength and direction of the association between the study variables. In order to increase the credibility of the test, the study performs bootstrapping based on 1,000 samples at 95\% confidence interval. Table 2 presents the results of the Kendall's Tau_b test statistic. Evidence from Table 2 shows that, with the exception of COPRA $\left(\tau_{b}=-0.104, \rho=0.288\right)$, CORN $\left(\tau_{b}=0.771, \rho=0.000\right)$, GREENCOFFEE $\left(\tau_{b}=0.332, \rho=0.000\right)$, MILLEDRICE $\left(\tau_{b}=0.752, \rho=\right.$ $0.000)$, MILET ( $\left.\tau_{b}=0.564, \rho=0.000\right)$, PALMKERNEL $\left(\tau_{b}=0.638, \rho=\right.$
$0.000)$ and SORGHUM $\left(\tau_{b}=0.558, \rho=0.000\right)$ have a significant positive relation with $\mathrm{CO}_{2}$. Nevertheless, statistical inferences cannot be made from descriptive statistics since Kendall's tau-b correlation and bootstrapping do not provide evidence of causation, therefore, the study estimates the validity of the relationship and causation using econometric techniques.

\section{Results and Discussion}

\subsection{Unit Root}

As a prerequisite for the ARDL bounds test co-integration, the series should be integrated at either I(0) or I(1). To meet the requirement, the study estimates the unit root test using Phillip-Perron's (PP), Kwiatkowski-Phillips-Schmidt-Shin (KPSS) and Vogelsang's breakpoint unit root tests in order to have a robust result. Vogelsang's breakpoint unit root test is estimated by taking into consideration the innovation outlier since PP and KPSS unit root tests may fail to test stationarity in the presence of structural breaks. Table 3 shows that the null hypothesis of a unit root cannot be rejected in the PP and Vogelsang's breakpoint tests at 5\% significance level, however, the null hypothesis of stationarity in the KPSS test is rejected at $5 \%$ significance level. In addition, the study rejects the null hypothesis of a unit root in the PP and Vogelsang's breakpoint tests at first difference based on 5\% significance level but cannot reject the null hypothesis of stationarity in the KPSS test at first difference based on 5\% significance level. Evidence from PP, KPSS and Vogelsang's breakpoint unit root tests shows that the series are integrated at I(1).

\subsection{ARDL Cointegration and Regression Analysis}

After establishing evidence that the series are integrated at I(1), the next step is to estimate the relationship between the variables using the ARDL method of cointegration (bounds test). Table 4 presents the ARDL bounds test results. Evidence from Table 4 shows that the F-statistic lies above the 10 and 5\% critical values of I(1) bound, showing a rejection of the null hypothesis of no co-integration relationship between $\mathrm{LCO}_{2}$, LCOPRA, LCORN, LGREENCOFFEE, LMILLEDRICE, LMILLET, LPALMKERNEL and LSORGHUM.

Table 1. Descriptive Statistic Analysis

\begin{tabular}{ccccccccc}
\hline Statistic & $\mathbf{C O}_{2}$ & COPRA & CORN & GREENCOFFEE & MILLEDRICE & MILLET & PALMKERNEL & SORGHUM \\
\hline Mean & $4,322.758$ & 14.21154 & 694.5385 & 44.28846 & 88.73077 & 128.6346 & 41.51923 & 199.0192 \\
Median & $3,305.801$ & 18 & 524 & 35 & 57.5 & 126 & 35 & 161.5 \\
Maximum & $10,102.59$ & 24 & 1,872 & 116 & 295 & 246 & 96 & 360 \\
Minimum & $1,345.789$ & 5 & 172 & 13 & 21 & 40 & 12 & 56 \\
Std. Dev. & $2,588.105$ & 6.601653 & 451.0033 & 27.08689 & 66.78591 & 48.47074 & 21.23398 & 99.18521 \\
Skewness & 0.822663 & -0.03152 & 0.765434 & 0.923516 & 1.261948 & 0.288108 & 1.301225 & 0.270886 \\
Kurtosis & 2.50408 & 1.346322 & 2.587095 & 3.055398 & 4.121345 & 2.28307 & 3.678993 & 1.464433 \\
Jarque-Bera & 6.398236 & 5.93369 & 5.447104 & 7.398286 & 16.52617 & 1.833028 & 15.67318 & 5.744881 \\
Probability & 0.040798 & 0.051465 & 0.065641 & 0.024745 & 0.000258 & 0.399911 & 0.000395 & 0.056561 \\
\hline
\end{tabular}




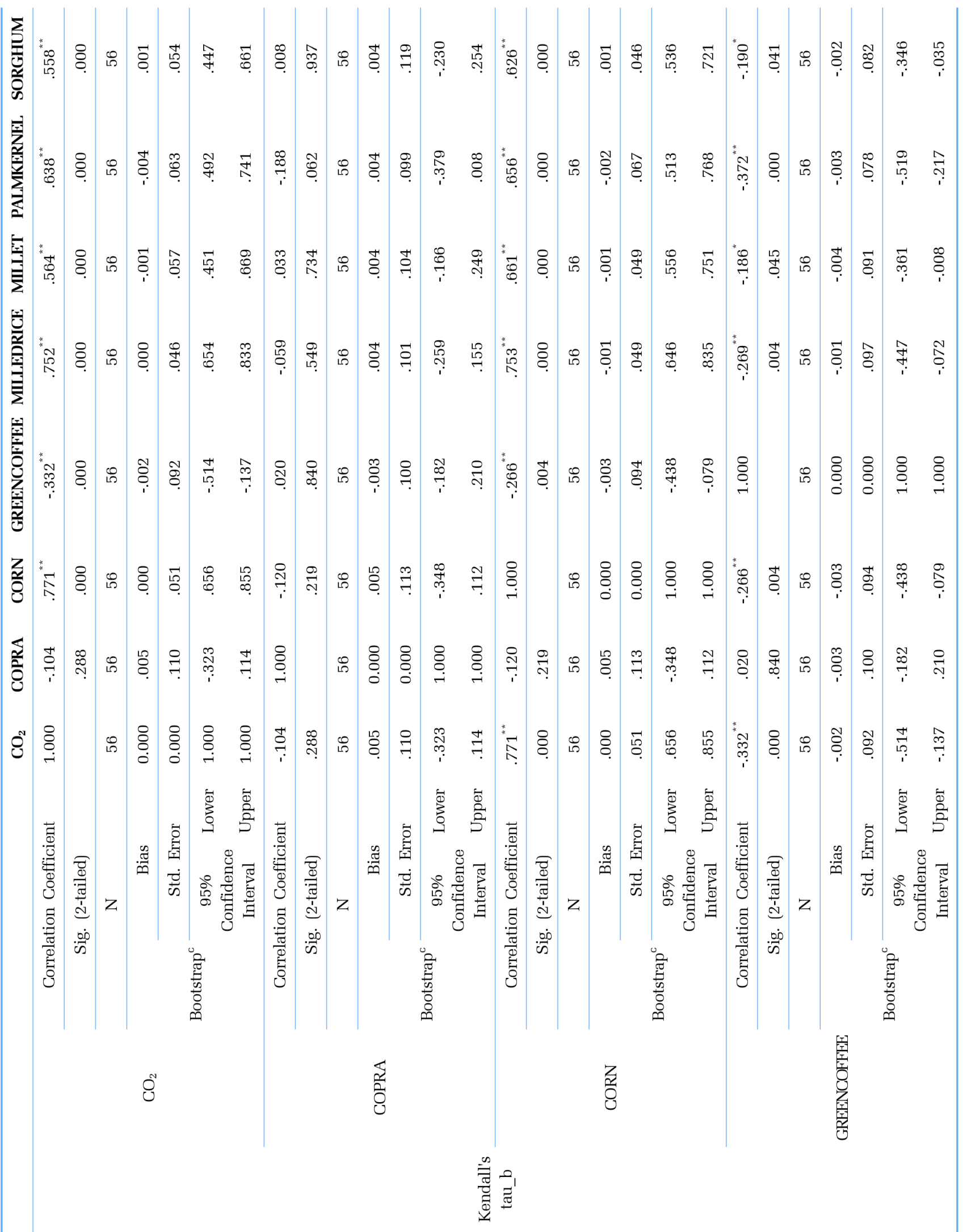




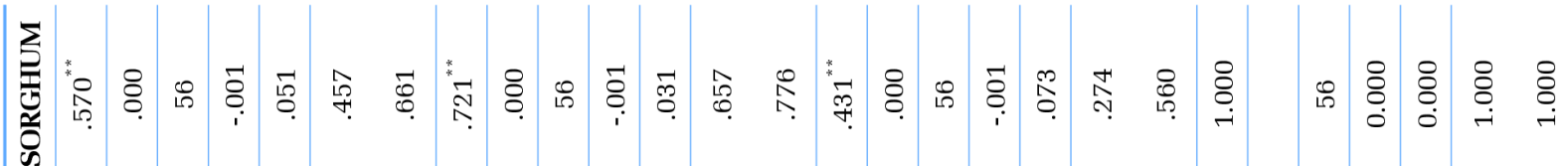



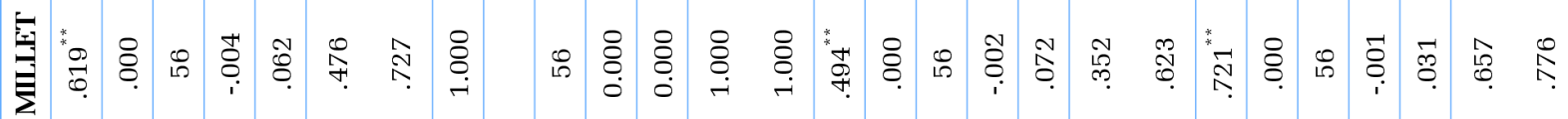



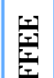

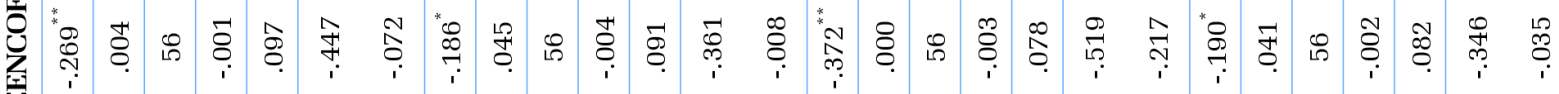
픙

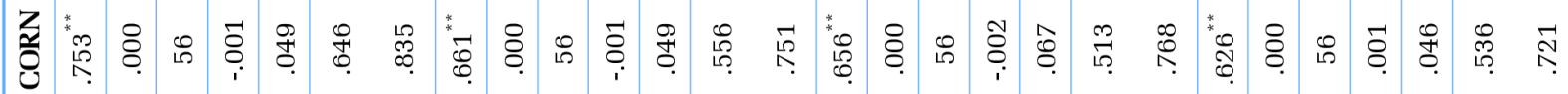
亲

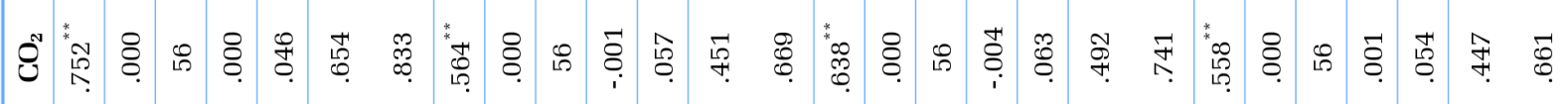

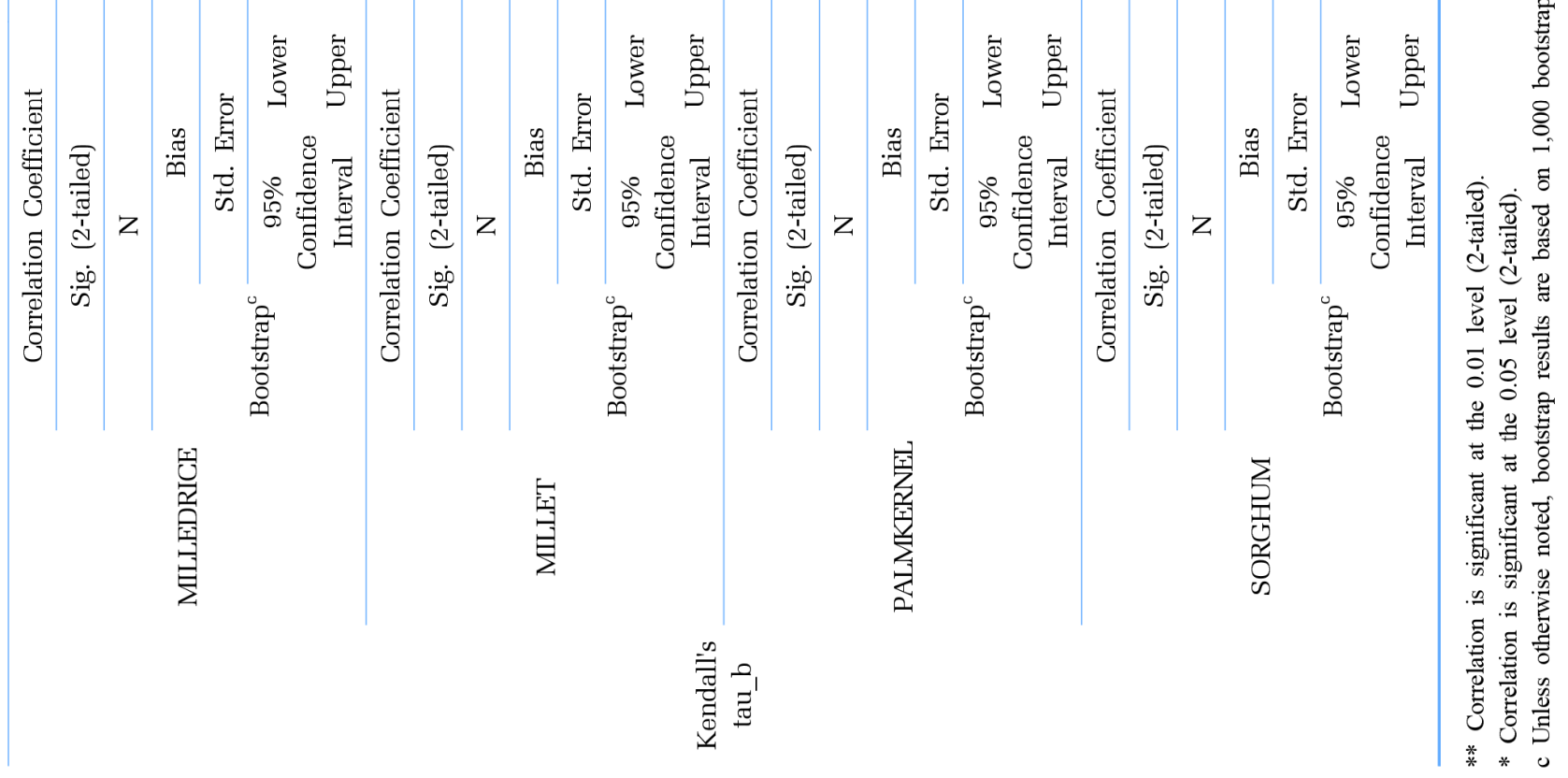




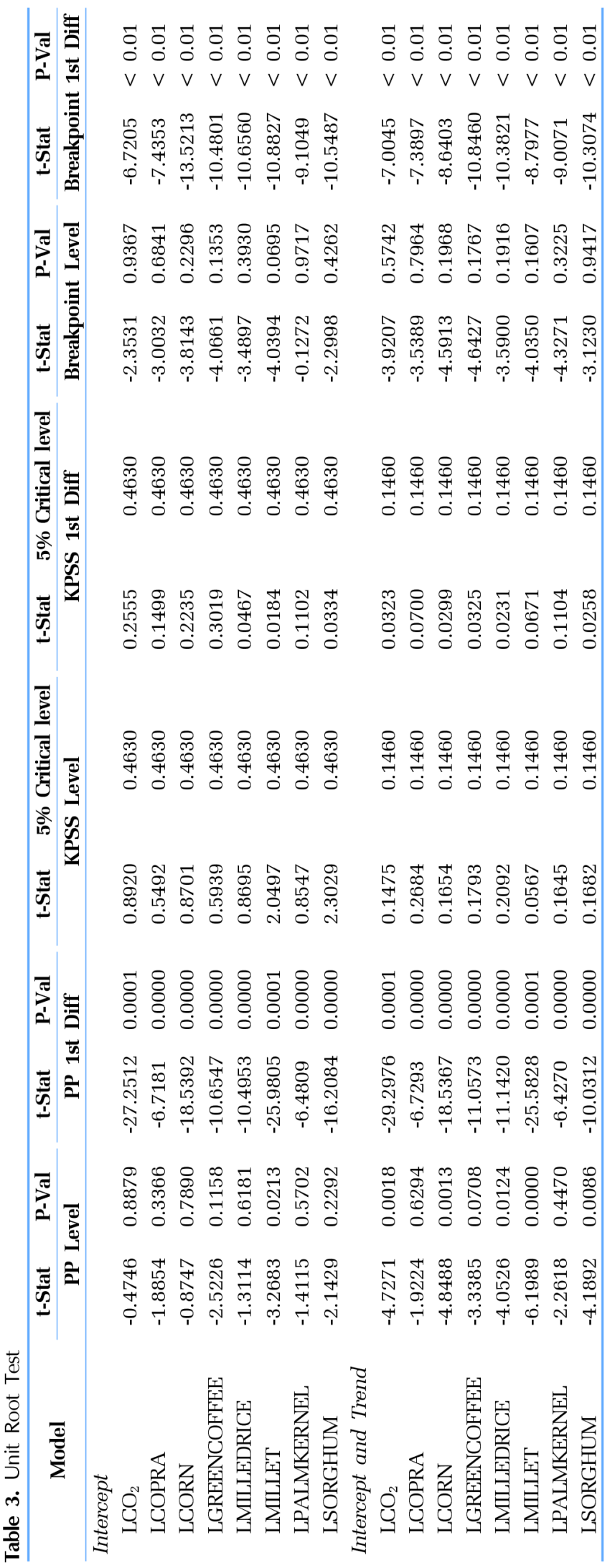

Table 4. ARDL Bounds Test

\begin{tabular}{lcc}
\hline \multicolumn{1}{c}{ Test Statistic } & Value & k \\
\hline F-statistic & 3.26 & 7 \\
Critical Value Bounds & & \\
$\quad$ Significance & I0 Bound & I1 Bound \\
$10 \%$ & 1.92 & 2.89 \\
$5 \%$ & 2.17 & 3.21 \\
$2.50 \%$ & 2.43 & 3.51 \\
$1 \%$ & 2.73 & 3.9 \\
\hline
\end{tabular}

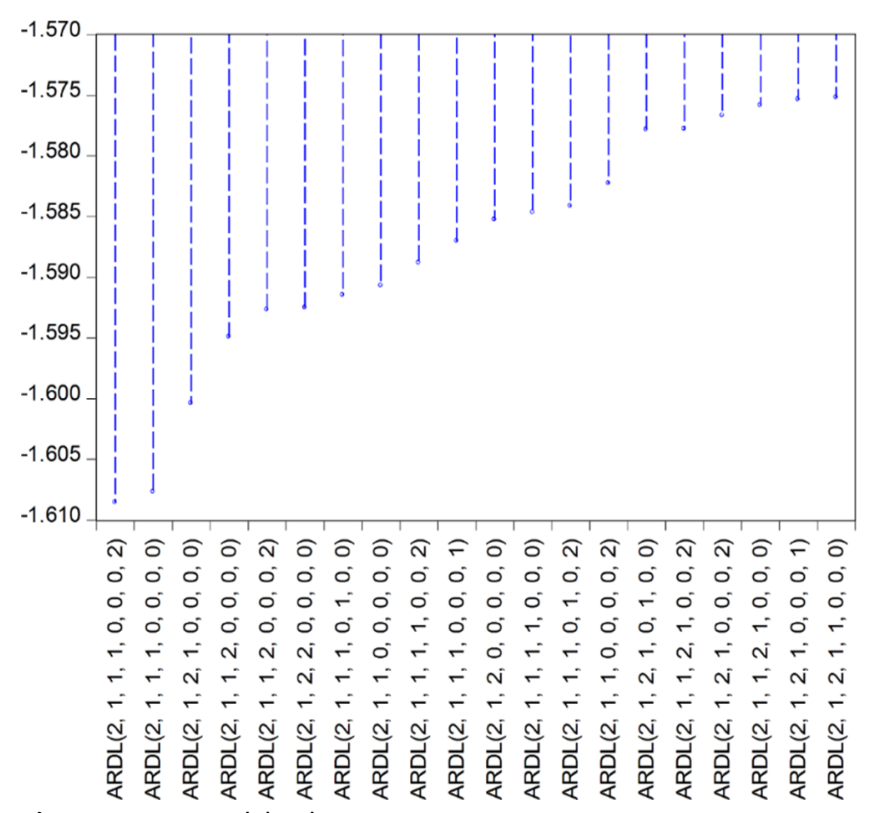

Fig. 3. ARDL model selection criterion.

After establishing a cointegration relationship among variables, the study employs the Akaike information criterion to select an optimal model for estimating the long-run equilibrium relationship. Fig. 3 shows the top twenty possible ARDL models selected by the Akaike information criterion. Akaike information criterion evaluated 4,374 models in order to select ARDL (2, 1, $1,1,0,0,0,2)$ as the optimal model for the ARDL regression analysis (Fig. 3).

Using the optimal model [ARDL $(2,1,1,1,0,0,0,2)]$, the long-run and short-run equilibrium relation $\mathrm{LCO}_{2}$, LCOPRA, LCORN, LGREENCOFFEE, LMILLEDRICE, LMILLET, LPALMKERNEL and LSORGHUM is estimated using the ARDL regression analysis based on the model specifications in Eq. (2), expressed as:

$$
\begin{aligned}
\text { Cointeq }= & L_{C O}-(0.0909 \times L C O P R A+0.9576 \times L C O R N-0.0522 \times \\
& \text { LGREENCOFFEE }+0.3665 \times \text { LMILLEDRICE }-1.6174 \times \\
& \text { LMLLET }-0.5245 \times L P A L M K E R N E L+0.2000 \times \\
& L S O R G H U M+4.6984)
\end{aligned}
$$

Where, $\beta_{0}=4.6984, \beta_{1}=0.0909, \beta_{2}=0.9576, \beta_{3}=-0.0522, \beta_{4}=$ $0.3665, \beta_{5}=-0.6174, \beta_{6}=-0.5245$ and $\beta_{7}=0.2000$ 
Table 5. ARDL Regression Analysis

\begin{tabular}{|c|c|c|c|c|}
\hline Variable & Coefficient & Std. Error & t-Statistic & Prob. \\
\hline \multicolumn{5}{|l|}{ Short Run Coefficients } \\
\hline LCOPRA & 0.2214 & 0.0574 & 3.8541 & $0.0004^{*}$ \\
\hline LCORN & 0.0035 & 0.0585 & 0.0592 & 0.9531 \\
\hline LGREENCOFFEE & 0.0383 & 0.0223 & 1.7175 & $0.0938^{* *}$ \\
\hline LMILLEDRICE & 0.0343 & 0.0466 & 0.7362 & 0.4660 \\
\hline LMILLET & -0.1366 & 0.0705 & -1.9361 & $0.0601^{*}$ \\
\hline LPALMKERNEL & -0.0985 & 0.0999 & -0.9852 & 0.3306 \\
\hline LSORGHUM & -0.1054 & 0.0510 & -2.0684 & $0.0453^{*}$ \\
\hline ECT $(-1)$ & -0.1754 & 0.0321 & -5.4714 & $0.0000^{*}$ \\
\hline \multicolumn{5}{|l|}{ Long Run Coefficients } \\
\hline LCOPRA & 0.0909 & 0.1939 & 0.4686 & 0.6419 \\
\hline LCORN & 0.9577 & 0.6863 & 1.3954 & 0.1708 \\
\hline LGREENCOFFEE & -0.0522 & 0.1506 & -0.3464 & 0.7309 \\
\hline LMILLEDRICE & 0.3665 & 0.3391 & 1.0808 & 0.2864 \\
\hline LMILLET & -0.6174 & 0.6202 & -0.9955 & 0.3256 \\
\hline LPALMKERNEL & -0.5245 & 0.6320 & -0.8300 & 0.4116 \\
\hline LSORGHUM & 0.2000 & 0.5391 & 0.3710 & 0.7127 \\
\hline $\mathrm{C}$ & 4.6984 & 1.9034 & 2.4685 & $0.0181^{*}$ \\
\hline
\end{tabular}

***rejection at $5 \%$ and $10 \%$ significance level

Table 5 presents a summary of the ARDL regression analysis. Evidence from Table 5 shows that the speed of adjustment (error correction term) $[\mathrm{ECT}(-1)=-0.18, \rho=0.000]$ is negative and significant at $1 \%$ level, showing evidence of a long-run equilibrium relationship running from LCOPRA, LCORN, LGREENCOFFEE, LMILLEDRICE, LMILLET, LPALMKERNEL and LSORGHUM to $\mathrm{LCO}_{2}$. There is no evidence of long-run elasticities from LCOPRA, LCORN, LGREENCOFFEE, LMILLEDRICE, LMILLET, LPALMKERNEL and LSORGHUM to $\mathrm{LCO}_{2}$ due to statistical insignificance. Nevertheless, evidence from Table 5 shows that the joint effect of the variables at constant will increase carbon dioxide emissions by $4.7 \%$ in the long-run.

Evidence of the short-run equilibrium relationship shows that a $1 \%$ increase in LCOPRA will increase $\mathrm{LCO}_{2}$ by $0.22 \%$, a $1 \%$ increase in LGREENCOFFEE will increase $\mathrm{LCO}_{2}$ by $0.03 \%$, a $1 \%$ increase in LMILLET will decrease $\mathrm{LCO}_{2}$ by $0.13 \%$ and a $1 \%$ increase in LSORGHUM will decrease $\mathrm{LCO}_{2}$ by $0.11 \%$ in the short-run.

\subsection{Diagnostic Test}

In order to estimate the independence of the residuals in the ARDL model, diagnostic and stability checks are examined to verify and validate the model. Table 6 presents the diagnostic tests applied to the ARDL model [ARDL $(2,1,1,1,0,0,0,2)]$. Evidence from Table 6 shows that the null hypothesis of no autocorrelation at lag order by the Breusch-Pagan-Godfrey Test cannot be rejected at the $5 \%$ significance level. The null hypothesis of no serial correlation exist at the lag order $\mathrm{h}$ by the Breusch-Godfrey Serial
Table 6. Diagnostic Test

\begin{tabular}{|c|c|c|c|}
\hline \multicolumn{4}{|c|}{ Heteroskedasticity Test: Breusch-Pagan-Godfrey } \\
\hline F-statistic & 1.6772 & Prob. $F(12,41)$ & 0.1082 \\
\hline \multicolumn{4}{|c|}{ Breusch-Godfrey Serial Correlation LM Test } \\
\hline F-statistic & 2.2941 & Prob. F(2,37) & 0.1150 \\
\hline \multicolumn{4}{|c|}{ Jarque-Bera Test } \\
\hline Jarque-Bera & 0.6215 & Prob. & 0.7329 \\
\hline \multicolumn{4}{|c|}{ Ramsey RESET Test } \\
\hline F-statistic & 1.6029 & Prob. $F(1,38)$ & 0.2132 \\
\hline
\end{tabular}

Correlation Lagrange-multiplier test cannot be rejected at the $5 \%$ significance level. In addition, the null hypothesis of normal distribution among residual using Jarque-Bera test cannot be rejected at the $5 \%$ significance level. The null hypothesis of no omitted variables within the ARDL model cannot be rejected at the $5 \%$ significance level. In other words, the ARDL model is robust and satisfies all diagnostic conditions to make unbiased estimates and statistical inferences.

The study employs the cumulative sum (CUSUM) and CUSUM of Squares tests to examine the constancy of cointegration space. Evidence from Fig. 4 shows that the plots of the CUSUM and CUSUM of Squares tests lie within the 5\% significance level, meaning that the specification of the ARDL model is stable to estimate the parameters of the long-run and the short-run equilibrium relationship. 

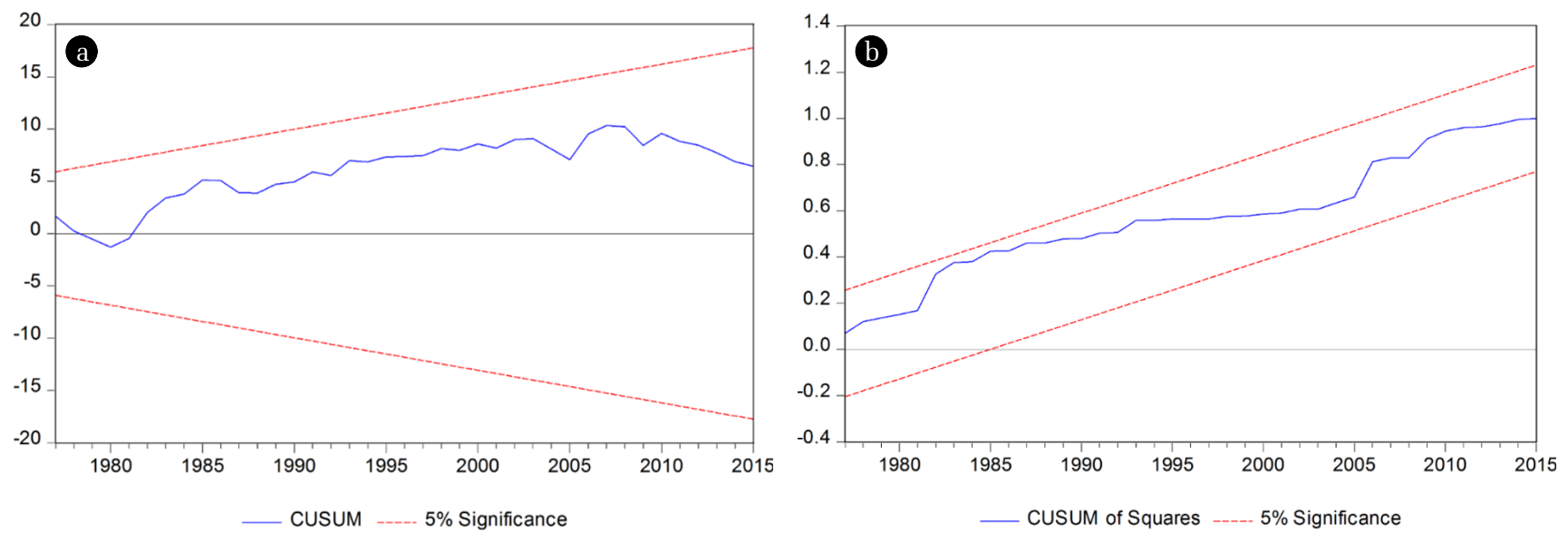

Fig. 4. The constancy of cointegration space (a) CUSUM test (b) CUSUM of squares test.

Table 7. Granger-causality Test

\begin{tabular}{|c|c|c|c|}
\hline Null Hypothesis: & Obs & F-Statistic & Prob. \\
\hline LCOPRA does not Granger Cause $\mathrm{LCO}_{2}$ & 54 & 0.2556 & 0.7755 \\
\hline $\mathrm{LCO}_{2}$ does not Granger Cause LCOPRA & & 0.7808 & 0.4637 \\
\hline LCORN does not Granger Cause $\mathrm{LCO}_{2}$ & 54 & 6.8133 & $0.0025^{*}$ \\
\hline $\mathrm{LCO}_{2}$ does not Granger Cause LCORN & & 2.8537 & 0.0672 \\
\hline LGREENCOFFEE does not Granger Cause $\mathrm{LCO}_{2}$ & 54 & 0.1172 & 0.8897 \\
\hline $\mathrm{LCO}_{2}$ does not Granger Cause LGREENCOFFEE & & 2.4777 & 0.0944 \\
\hline LMILLEDRICE does not Granger Cause $\mathrm{LCO}_{2}$ & 54 & 4.6591 & $0.0140^{*}$ \\
\hline $\mathrm{LCO}_{2}$ does not Granger Cause LMILLEDRICE & & 6.4341 & $0.0033^{*}$ \\
\hline LMILLET does not Granger Cause $\mathrm{LCO}_{2}$ & 54 & 5.4505 & $0.0073^{*}$ \\
\hline $\mathrm{LCO}_{2}$ does not Granger Cause LMILLET & & 8.6384 & $0.0006^{*}$ \\
\hline LPALMKERNEL does not Granger Cause $\mathrm{LCO}_{2}$ & 54 & 0.5122 & 0.6024 \\
\hline $\mathrm{LCO}_{2}$ does not Granger Cause LPALMKERNEL & & 3.2720 & $0.0464^{*}$ \\
\hline LSORGHUM does not Granger Cause $\mathrm{LCO}_{2}$ & 54 & 3.9091 & $0.0266^{*}$ \\
\hline $\mathrm{LCO}_{2}$ does not Granger Cause LSORGHUM & & 4.3243 & $0.0186^{*}$ \\
\hline
\end{tabular}

*rejection at $5 \%$ significance level

\subsection{Granger-causality}

The study examines the direction of causality between $\mathrm{LCO}_{2}$, LCOPRA, LCORN, LGREENCOFFEE, LMILLEDRICE, LMILLET, LPALMKERNEL and LSORGHUM using the Granger-causality test since the ARDL model only estimates the long-run and short-run equilibrium relationships existing between variables $[25,31]$. Table 7 presents a summary of the Granger causality test. The null hypothesis that LCORN does not Granger Cause $\mathrm{LCO}_{2}$, LMILLEDRICE does not Granger Cause $\mathrm{LCO}_{2}, \mathrm{LCO}_{2}$ does not Granger Cause LMILLEDRICE, LMILLET does not Granger Cause $\mathrm{LCO}_{2}, \mathrm{LCO}_{2}$ does not Granger Cause LMILLET, $\mathrm{LCO}_{2}$ does not Granger Cause LPALMKERNEL, LSORGHUM does not Granger Cause $\mathrm{LCO}_{2}$ and $\mathrm{LCO}_{2}$ does not Granger Cause LSORGHUM is rejected at the $5 \%$ significance level. Evidence from Table 7 shows bidirectional causality between; LMILLEDRICE $\leftrightarrow \mathrm{LCO}_{2}$, LMILLET $\leftrightarrow \mathrm{LCO}_{2}$ and LSORGHUM $\leftrightarrow \mathrm{LCO}_{2}$, and a unidirectional causality running from; LCORN $\rightarrow \mathrm{LCO}_{2}$ and $\mathrm{LCO}_{2} \rightarrow$ LPALMKERNEL.

\subsection{Impulse-response Analysis}

The study employs the impulse-response analysis to examine the response of $\mathrm{LCO}_{2}$, LCOPRA, LCORN, LGREENCOFFEE, LMILLEDRICE, LMILLET, LPALMKERNEL and LSORGHUM to random innovations in each other that is not explained by the Granger-causality test. Significantly, the impulse-response analysis avoids the orthogonal problems related with out-of-sample Granger-causality tests. Fig. 5 depicts the Impulse-Response of carbon dioxide emissions to Cholesky One S.D. Innovations in other variables.

Evidence from Fig. 5 shows that the response of carbon dioxide emissions to green coffee production is insignificant within the 10-period horizon. The initial response of carbon dioxide emissions to copra production, corn production, palm kernel production, milled rice production, millet production and sorghum production is significant. However, a one standard deviation shock to copra and millet production increases carbon dioxide emissions to the 2-period horizon and decreases thereafter. A one standard deviation 

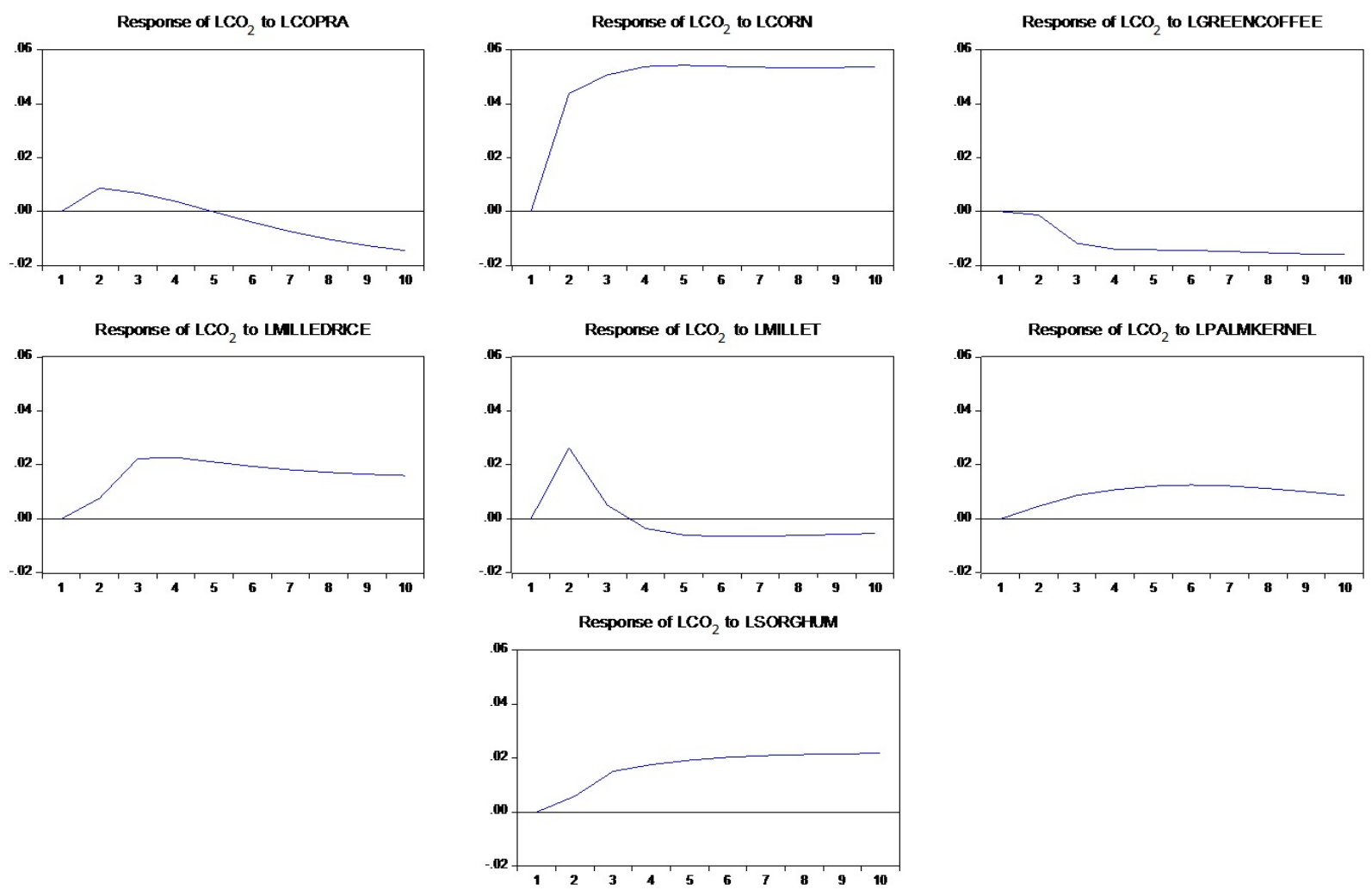

Fig. 5. Impulse-response of $\mathrm{LCO}_{2}$ to Cholesky One S.D.
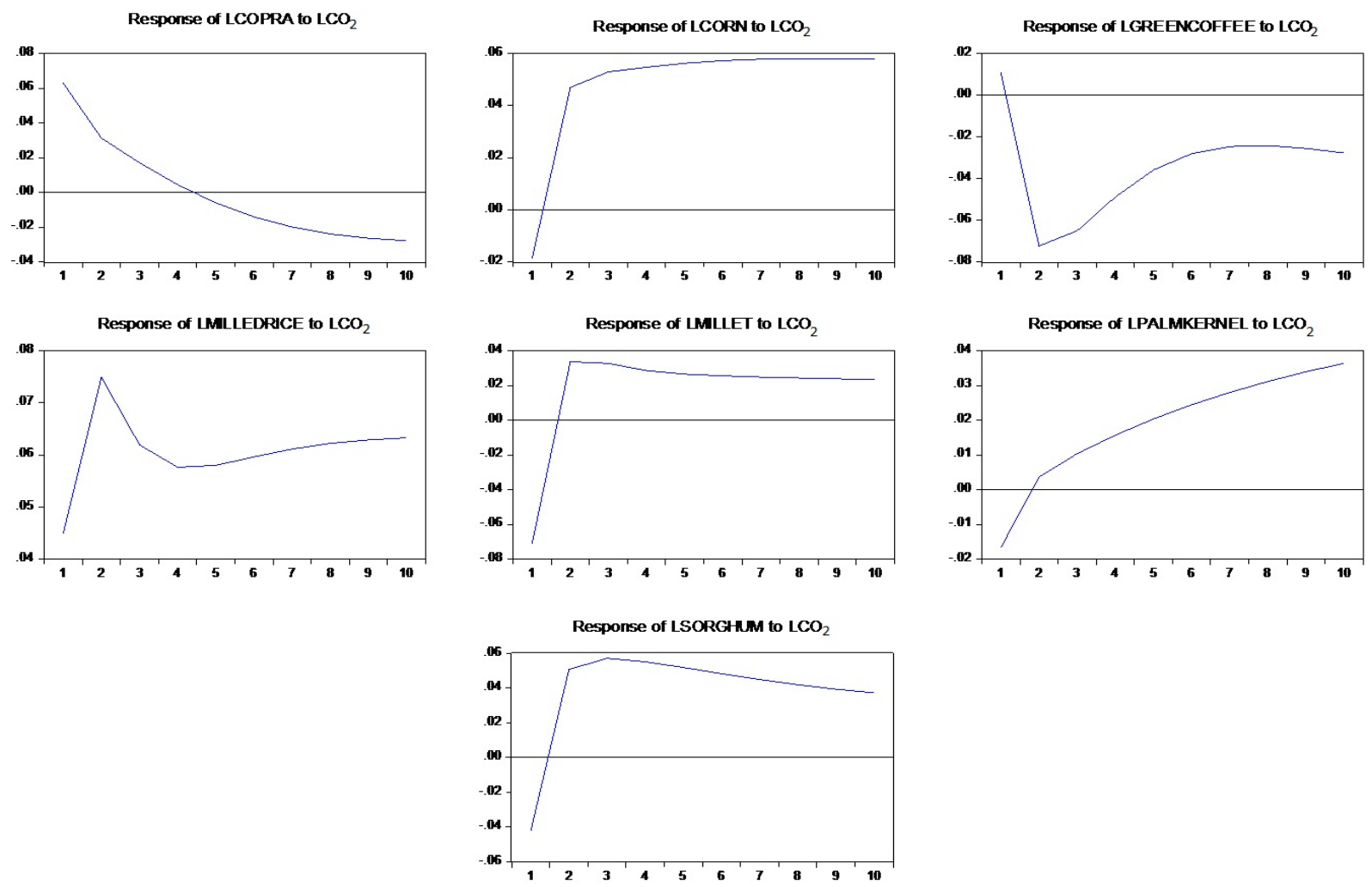

Fig. 6. Impulse-response of other variables to Cholesky One S.D. Innovations in $\mathrm{LCO}_{2}$. 
shock to corn and sorghum production causes carbon dioxide emissions to peak at the 4-period horizon and increases at a constant rate thereafter. A one standard deviation shock to milled rice and palm kernel production causes carbon dioxide emissions to peak at the 3-period horizon and decreases gradually with time. Both Granger-causality and impulse-response analysis confirm that green coffee production has no effect on carbon dioxide emissions in Ghana.

Fig. 6 depicts the Impulse-Response of other variables to Cholesky One S.D. Innovations in carbon dioxide emissions. Evidence from Fig. 6 shows that the initial response of corn, green coffee, millet, palm kernel and sorghum production to carbon dioxide emissions are not within the first-period horizon. However, a one standard deviation shock to carbon dioxide emissions peaks copra and green coffee production to the 1-period horizon decreases thereafter and die off after 4-period horizon. A one standard deviation shock to carbon dioxide emissions peaks millet and corn production to the 2-period horizon and increases at a constant rate thereafter. A one standard deviation shock to carbon dioxide emission peaks milled rice and sorghum production to the 2-period horizon and decreases thereafter.

\section{Conclusions and Policy Recommendation}

The study made an attempt to answer the question: Is there a causal-effect between agricultural production and carbon dioxide emissions in Ghana? By employing a time series data spanning from 1960 to 2015 using the ARDL method. Prior to estimating the econometric method, Kendall's tau-b and bootstrapping were done to examine the strength of the linear relationship. Evidence from PP, KPSS and Vogelsang's breakpoint unit root tests shows that the variables are integrated at I(1). The ARDL bounds test showed an evidence of co-integration relationship between the variables.

Using the optimal model [ARDL $(2,1,1,1,0,0,0,2)]$, there was evidence of a long-run equilibrium relationship running from copra production, corn production, green coffee production, milled rice production, millet production, palm kernel production and sorghum production to carbon dioxide emissions. Even though there was no evidence of long-run elasticities from individual variables however, the joint effect of the variables at constant will increase carbon dioxide emissions by $4.7 \%$ in the long-run.
Evidence from the short-run equilibrium relationship shows that, a $1 \%$ increase in copra production will increase carbon dioxide emissions by $0.22 \%$, a $1 \%$ increase in green coffee production will increase carbon dioxide emissions by $0.03 \%$, a $1 \%$ increase in millet production will decrease carbon dioxide emissions by $0.13 \%$ and a $1 \%$ increase in sorghum production will decrease carbon dioxide emissions by $0.11 \%$ in the short-run.

Evidence from the Granger-causality shows bidirectional causality between milled rice production and carbon dioxide emissions, millet production and carbon dioxide emissions and, sorghum production and carbon dioxide emissions; and a unidirectional causality running from corn production to carbon dioxide emissions and carbon dioxide emissions to palm kernel production. Evidence from both Granger-causality and impulse-response analysis showed that palm kernel production has no effect on carbon dioxide emissions in Ghana.

In order to account for the future effect of variables on carbon dioxide emissions in the VAR, the study employs the Cholesky's method of variance decomposition as showed in Table 8.



Fig. 7. Variance decomposition of other variables' response to carbon dioxide emissions.

Table 8. Variance Decomposition of Carbon Dioxide Emissions

\begin{tabular}{|c|c|c|c|c|c|c|c|c|c|}
\hline Period & S.E. & $\mathrm{LCO}_{2}$ & LCOPRA & LCORN & LGREENCOFFEE & LMILLEDRICE & LMILLET & LPALMKERNEL & LSORGHUM \\
\hline 1 & 0.11685 & 100 & 0 & 0 & 0 & 0 & 0 & 0 & 0 \\
\hline 2 & 0.14662 & 86.9453 & 0.35318 & 8.94048 & 0.00789 & 0.27106 & 3.22030 & 0.10250 & 0.15927 \\
\hline 3 & 0.17079 & 78.0984 & 0.42082 & 15.38632 & 0.48460 & 1.91178 & 2.46339 & 0.33694 & 0.89780 \\
\hline 4 & 0.19197 & 71.6413 & 0.37107 & 20.02652 & 0.91686 & 2.92511 & 1.98407 & 0.58426 & 1.55080 \\
\hline 5 & 0.21042 & 67.0416 & 0.30891 & 23.31428 & 1.21856 & 3.43967 & 1.73285 & 0.82105 & 2.12312 \\
\hline 6 & 0.22682 & 63.6300 & 0.29718 & 25.70485 & 1.45313 & 3.69798 & 1.57380 & 1.01455 & 2.62850 \\
\hline 7 & 0.24176 & 60.9753 & 0.35598 & 27.52104 & 1.65632 & 3.82264 & 1.45568 & 1.14754 & 3.06547 \\
\hline 8 & 0.25565 & 58.8220 & 0.48085 & 28.96463 & 1.84009 & 3.87464 & 1.35894 & 1.22090 & 3.43795 \\
\hline 9 & 0.26876 & 57.0160 & 0.65643 & 30.15964 & 2.00636 & 3.88598 & 1.27532 & 1.24512 & 3.75518 \\
\hline 10 & 0.28128 & 55.4616 & 0.86431 & 31.18350 & 2.15429 & 3.87430 & 1.20098 & 1.23323 & 4.02775 \\
\hline
\end{tabular}


S1 Table. Cholesky Ordering: LCOPRA LCORN LGREENCOFFEE LMILLEDRICE LMILLET LPALMKERNEL LSORGHUM

\begin{tabular}{cccccccccc}
\hline \multicolumn{1}{c}{ Period } & S.E. & LCO $_{2}$ & LCOPRA & LCORN & LGREENCOFFEE & LMILLEDRICE & LMILLET & LPALMKERNEL & LSORGHUM \\
\hline 1 & 0.2203 & 8.1405 & 91.8595 & 0 & 0 & 0 & 0 & 0 & 0 \\
2 & 0.2921 & 5.7738 & 92.5980 & 0.0687 & 0.1690 & 0.4424 & 0.1482 & 0.4088 & 0.3911 \\
3 & 0.3375 & 4.5785 & 91.2495 & 0.5343 & 0.3062 & 0.9908 & 0.1256 & 1.4394 & 0.7758 \\
4 & 0.3696 & 3.8342 & 88.8057 & 1.4061 & 0.4539 & 1.2166 & 0.1908 & 2.9503 & 1.1423 \\
5 & 0.3935 & 3.4048 & 85.6704 & 2.6537 & 0.5715 & 1.2474 & 0.2755 & 4.7124 & 1.4644 \\
6 & 0.4123 & 3.2178 & 82.1890 & 4.1770 & 0.6384 & 1.1958 & 0.3494 & 6.4801 & 1.7525 \\
7 & 0.4276 & 3.2086 & 78.6629 & 5.8445 & 0.6617 & 1.1237 & 0.4045 & 8.0757 & 2.0185 \\
8 & 0.4402 & 3.3204 & 75.3169 & 7.5313 & 0.6579 & 1.0601 & 0.4411 & 9.4062 & 2.2662 \\
9 & 0.4508 & 3.5075 & 72.2950 & 9.1385 & 0.6413 & 1.0157 & 0.4624 & 10.4453 & 2.4942 \\
10 & 0.4598 & 3.7359 & 69.6706 & 10.5995 & 0.6211 & 0.9921 & 0.4726 & 11.2094 & 2.6990
\end{tabular}

Variance Decomposition of LCORN:

\begin{tabular}{cccccccccc}
\hline Period & S.E. & LCO $_{2}$ & LCOPRA & LCORN & LGREENCOFFEE & LMILLEDRICE & LMILLET & LPALMKERNEL & LSORGHUM \\
\hline 1 & 0.2300 & 0.6574 & 5.3075 & 94.0351 & 0 & 0 & 0 & 0 & 0 \\
2 & 0.2712 & 3.4693 & 3.8790 & 80.7249 & 0.3540 & 3.1225 & 4.1152 & 0.8281 & 3.5069 \\
3 & 0.2934 & 6.2221 & 3.3271 & 76.1867 & 0.4093 & 3.2701 & 4.3950 & 1.2490 & 1.4425 \\
4 & 0.3100 & 8.6867 & 3.0681 & 73.1743 & 0.5078 & 3.2313 & 4.1270 & 5.9407 \\
5 & 0.3246 & 10.9217 & 2.9543 & 70.7061 & 0.6778 & 3.2034 & 3.8327 & 1.4885 & 6.7625 \\
6 & 0.3383 & 12.9226 & 2.9211 & 68.6034 & 0.8807 & 3.1935 & 3.5676 & 1.4604 & 6.4506 \\
7 & 0.3513 & 14.6873 & 2.9344 & 66.7958 & 1.0799 & 3.1946 & 3.3340 & 1.4016 \\
8 & 0.3639 & 16.2299 & 2.9733 & 65.2373 & 1.2577 & 3.2003 & 3.1278 & 1.3324 \\
9 & 0.3761 & 17.5742 & 3.0244 & 63.8905 & 1.4100 & 3.2067 & 2.9450 & 1.2617 & 6.5725 \\
10 & 0.3880 & 18.7473 & 3.0784 & 62.7228 & 1.5387 & 3.2119 & 2.7820 & 1.1935
\end{tabular}

Variance Decomposition of LGREENCOFFEE:

\begin{tabular}{cccccccccc}
\hline Period & S.E. & LCO $_{2}$ & LCOPRA & LCORN & LGREENCOFFEE & LMILLEDRICE & LMILLET & LPALMKERNEL & LSORGHUM \\
\hline 1 & 0.5369 & 0.0391 & 3.0419 & 1.5410 & 95.3780 & 0 & 0 & 0 & 0 \\
2 & 0.6411 & 1.2997 & 2.6147 & 2.8546 & 88.8895 & 0.0574 & 0.2070 & 0.0774 & 3.9997 \\
3 & 0.6787 & 2.0776 & 2.3614 & 3.7322 & 84.3445 & 0.1418 & 0.1951 & 0.0952 & 7.0523 \\
4 & 0.6948 & 2.4769 & 2.2777 & 4.2655 & 81.7326 & 0.2452 & 0.1931 & 0.3783 & 8.4309 \\
5 & 0.7032 & 2.6783 & 2.3587 & 4.5196 & 80.1508 & 0.3091 & 0.2041 & 0.8943 & 8.8852 \\
6 & 0.7088 & 2.7929 & 2.5859 & 4.6001 & 79.0468 & 0.3351 & 0.2217 & 1.4635 & 8.9540 \\
7 & 0.7132 & 2.8777 & 2.9310 & 4.5901 & 78.1782 & 0.3421 & 0.2382 & 1.9479 & 8.8948 \\
8 & 0.7170 & 2.9609 & 3.3575 & 4.5458 & 77.4424 & 0.3425 & 0.2501 & 2.2939 & 8.8069 \\
9 & 0.7205 & 3.0576 & 3.8257 & 4.5062 & 76.7833 & 0.3411 & 0.2572 & 2.5072 & 8.7217 \\
10 & 0.7239 & 3.1759 & 4.2991 & 4.4988 & 76.1607 & 0.3395 & 0.2607 & 2.6183 & 8.6469 \\
\hline
\end{tabular}

Variance Decomposition of LMILLEDRICE:

\begin{tabular}{cccccccccc}
\hline Period & S.E. & LCO $_{2}$ & LCOPRA & LCORN & LGREENCOFFEE & LMILLEDRICE & LMILLET & LPALMKERNEL & LSORGHUM \\
\hline 1 & 0.2635 & 2.9209 & 0.2255 & 9.2552 & 0.0074 & 87.5910 & 0 & 0 & 0 \\
2 & 0.3149 & 7.7014 & 0.1744 & 14.7272 & 0.0783 & 71.8023 & 5.2149 & 0.1884 & 0.1131 \\
3 & 0.3392 & 9.9716 & 0.2193 & 18.9945 & 0.2963 & 63.3600 & 5.5819 & 0.7568 \\
4 & 0.3572 & 11.5958 & 0.3630 & 21.6677 & 0.2895 & 57.5995 & 5.3107 & 1.2615 & 1.5127 \\
5 & 0.3727 & 13.0750 & 0.5671 & 23.5649 & 0.2941 & 53.1625 & 4.9836 & 1.9123 \\
6 & 0.3870 & 14.5001 & 0.8002 & 25.0558 & 0.4012 & 49.5045 & 4.6739 & 1.5810 & 3.4833 \\
7 & 0.4006 & 15.8555 & 1.0407 & 26.3038 & 0.5749 & 46.3665 & 4.3908 & 1.5571 & 3.9108 \\
8 & 0.4139 & 17.1133 & 1.2734 & 27.3959 & 0.7661 & 43.6162 & 4.1340 & 1.4953 & 4.2059 \\
9 & 0.4269 & 18.2577 & 1.4884 & 28.3818 & 0.9463 & 41.1769 & 3.9017 & 1.4214 & 4.4258 \\
10 & 0.4397 & 19.2866 & 1.6802 & 29.2890 & 1.1047 & 38.9972 & 3.6916 & 1.3467 & 4.6040 \\
\hline
\end{tabular}




\begin{tabular}{|c|c|c|c|c|c|c|c|c|c|}
\hline \multicolumn{10}{|c|}{ Variance Decomposition of LMILLET: } \\
\hline Period & S.E. & $\mathrm{LCO}_{2}$ & LCOPRA & LCORN & LGREENCOFFEE & LMILLEDRICE & LMILLET & LPALMKERNEL & LSORGHUM \\
\hline 1 & 0.2465 & 8.2823 & 3.8292 & 23.1972 & 4.6910 & 4.2304 & 55.7698 & 0 & 0 \\
\hline 2 & 0.2719 & 8.3360 & 4.4294 & 21.8730 & 4.1676 & 12.0139 & 48.1975 & 0.0377 & 0.9448 \\
\hline 3 & 0.2818 & 9.1078 & 5.0771 & 22.8491 & 3.8815 & 12.2001 & 45.6699 & 0.1229 & 1.0916 \\
\hline 4 & 0.2875 & 9.7318 & 5.3757 & 23.4612 & 3.7431 & 12.0275 & 44.0455 & 0.3228 & 1.2926 \\
\hline 5 & 0.2916 & 10.2890 & 5.4708 & 23.8095 & 3.6390 & 11.8689 & 42.8851 & 0.5489 & 1.4889 \\
\hline 6 & 0.2948 & 10.8144 & 5.4594 & 24.0436 & 3.5679 & 11.7367 & 41.9908 & 0.7499 & 1.6374 \\
\hline 7 & 0.2975 & 11.3147 & 5.3959 & 24.2242 & 3.5288 & 11.6234 & 41.2543 & 0.9153 & 1.7436 \\
\hline 8 & 0.3000 & 11.7895 & 5.3145 & 24.3791 & 3.5134 & 11.5210 & 40.6125 & 1.0474 & 1.8226 \\
\hline 9 & 0.3022 & 12.2384 & 5.2364 & 24.5237 & 3.5134 & 11.4237 & 40.0275 & 1.1502 & 1.8868 \\
\hline 10 & 0.3044 & 12.6626 & 5.1730 & 24.6678 & 3.5222 & 11.3273 & 39.4759 & 1.2273 & 1.9439 \\
\hline \multicolumn{10}{|c|}{ Variance Decomposition of LPALMKERNEL: } \\
\hline Period & S.E. & $\mathrm{LCO}_{2}$ & LCOPRA & LCORN & LGREENCOFFEE & LMILLEDRICE & LMILLET & LPALMKERNEL & LSORGHUM \\
\hline 1 & 0.1142 & 2.1324 & 1.3371 & 0.0794 & 0.5083 & 0.2083 & 2.4158 & 93.3187 & 0 \\
\hline 2 & 0.1563 & 1.1938 & 5.8410 & 2.1724 & 1.0349 & 0.1456 & 4.4044 & 84.9390 & 0.2688 \\
\hline 3 & 0.1815 & 1.2125 & 10.7726 & 2.5870 & 2.0376 & 0.1358 & 4.1874 & 78.8273 & 0.2398 \\
\hline 4 & 0.1997 & 1.6187 & 15.8778 & 2.4046 & 3.1488 & 0.1389 & 3.7696 & 72.8281 & 0.2136 \\
\hline 5 & 0.2143 & 2.3087 & 20.6688 & 2.0929 & 4.1639 & 0.1291 & 3.4025 & 67.0262 & 0.2080 \\
\hline 6 & 0.2268 & 3.2193 & 24.7893 & 1.9884 & 4.9790 & 0.1155 & 3.0948 & 61.5767 & 0.2369 \\
\hline 7 & 0.2383 & 4.2954 & 28.0305 & 2.2928 & 5.5728 & 0.1071 & 2.8320 & 56.5495 & 0.3198 \\
\hline 8 & 0.2493 & 5.4861 & 30.3190 & 3.0815 & 5.9649 & 0.1098 & 2.6021 & 51.9665 & 0.4701 \\
\hline 9 & 0.2600 & 6.7441 & 31.6924 & 4.3322 & 6.1892 & 0.1267 & 2.3981 & 47.8281 & 0.6891 \\
\hline 10 & 0.2707 & 8.0278 & 32.2667 & 5.9605 & 6.2821 & 0.1592 & 2.2154 & 44.1216 & 0.9667 \\
\hline \multicolumn{10}{|c|}{ Variance Decomposition of LSORGHUM: } \\
\hline Period & S.E. & $\mathrm{LCO}_{2}$ & LCOPRA & LCORN & LGREENCOFFEE & LMILLEDRICE & LMILLET & LPALMKERNEL & LSORGHUM \\
\hline 1 & 0.2491 & 2.8545 & 2.4133 & 27.7711 & 0.2596 & 2.2023 & 28.9982 & 0.0981 & 35.4028 \\
\hline 2 & 0.2945 & 5.0135 & 3.7663 & 30.5979 & 1.9254 & 4.0926 & 21.3408 & 0.9548 & 32.3089 \\
\hline 3 & 0.3212 & 7.3813 & 4.9316 & 33.3899 & 1.9829 & 3.9694 & 18.0473 & 1.6900 & 28.6075 \\
\hline 4 & 0.3397 & 9.2374 & 5.7180 & 34.8785 & 1.8460 & 3.9708 & 16.1486 & 1.9364 & 26.2644 \\
\hline 5 & 0.3535 & 10.6801 & 6.2589 & 35.7154 & 1.7242 & 4.0601 & 14.9153 & 1.9431 & 24.7029 \\
\hline 6 & 0.3643 & 11.8163 & 6.6191 & 36.2299 & 1.6331 & 4.1652 & 14.0583 & 1.8674 & 23.6106 \\
\hline 7 & 0.3728 & 12.7348 & 6.8346 & 36.5625 & 1.5671 & 4.2594 & 13.4374 & 1.7850 & 22.8192 \\
\hline 8 & 0.3796 & 13.4998 & 6.9351 & 36.7838 & 1.5207 & 4.3367 & 12.9723 & 1.7255 & 22.2262 \\
\hline 9 & 0.3852 & 14.1546 & 6.9491 & 36.9347 & 1.4904 & 4.3976 & 12.6124 & 1.6950 & 21.7664 \\
\hline 10 & 0.3900 & 14.7278 & 6.9029 & 37.0407 & 1.4738 & 4.4443 & 12.3244 & 1.6892 & 21.3969 \\
\hline
\end{tabular}

Policy Implications for Ghana: Evidence from Table 8 shows that, $31 \%$ of future fluctuations in carbon dioxide emissions are due to shocks in corn production, $4 \%$ of future fluctuations in carbon dioxide emissions are due to shocks in sorghum production, $4 \%$ of future fluctuations in carbon dioxide emissions are due to shocks in milled rice production, $2 \%$ of future fluctuations in carbon dioxide emissions are due to shocks in green coffee production, $1 \%$ of future fluctuations in carbon dioxide emissions are due to shocks in palm kernel production, $1 \%$ of future fluctuations in carbon dioxide emissions are due to shocks in millet production and $1 \%$ of future fluctuations in carbon dioxide emissions are due to shocks in copra production. Evidence from Fig. 7 shows that $19 \%$ of future fluctuations in milled rice production are due to shocks in carbon dioxide emissions, $19 \%$ of future fluctuations in corn production are due to shocks in carbon dioxide emissions, $15 \%$ of future fluctuations in sorghum production are due to shocks in carbon dioxide emissions, $13 \%$ of future fluctuations in millet production are due to shocks in carbon dioxide emissions, $8 \%$ of future fluctuations in palm kernel production are due to shocks in carbon dioxide emissions, $4 \%$ of future fluctuations in copra production are due to shocks in carbon dioxide emissions and $3 \%$ of future fluctuations in green coffee production are due to shocks in carbon dioxide emissions (For details, see: S1 Table).

Even though some absorbed quantities of carbon dioxide play a critical role in the manufacture of food in plants through a process of photosynthesis. However, extreme levels of carbon dioxide emissions that interfere with the climate system and threaten agricultural production are dangerous to the global food security. According to Asumadu-Sarkodie and Owusu [15], the agricultural sector is one of the major drivers in Ghana's economy growth with 
$66.2 \%$ from crop production. Evidence from the study shows that there is a causal effect between carbon dioxide emissions and agricultural production in Ghana. As a result, there is the need for the Government of Ghana is integrate climate change risk options, early warning signs and climate change adaptation options into the national policies, strategies and planning in order to reduce unsustainable agricultural practices while boosting agricultural production. There is the need for a paradigm shift in Ghana's agricultural sector input-intensive methods to a sustainable and robust food production system. This requires governmental policies that ensure equal access to technical know-how, modern technologies for sustainable farm practices and management, financial services for farmers, access to markets and opportunities for value-added technologies. Efforts that support and promote institutional research into sustainable agricultural technologies that improve local crops and livestock production are essential in Ghana.

\section{References}

1. United Nations. Global Sustainable Development Report. 2015.

2. Owusu P, Asumadu-Sarkodie S. A review of renewable energy sources, sustainability issues and climate change mitigation. Cogent Eng. 2016;3:1167990.

3. Asumadu-Sarkodie S, Owusu P. A review of ghana's energy sector national energy statistics and policy framework. Cogent Eng. 2016;3:1155274.

4. Asumadu-Sarkodie S, Owusu PA. Feasibility of biomass heating system in Middle East Technical University, Northern Cyprus Campus. Cogent Eng. 2016;3:1134304.

5. Owusu PA, Asumadu-Sarkodie S, Ameyo P. A review of Ghana's water resource management and the future prospect. Cogent Eng. 2016;3:1164275.

6. Mohiuddin O, Asumadu-Sarkodie S, Obaidullah M. The relationship between carbon dioxide emissions, energy consumption, and GDP: A recent evidence from Pakistan. Cogent Eng. 2016;3:1210491.

7. Asumadu-Sarkodie S, Owusu PA. Recent evidence of the relationship between carbon dioxide emissions, energy use, GDP and population in Ghana: A linear regression approach. Energ. Source. Part B. 2016. Available from: https://dx.doi.org/10.1080/ 15567249.2016.1208304

8. Asumadu-Sarkodie S, Owusu PA. A review of Ghana's solar energy potential. AIMS Energy 2016;4:675-696.

9. FAO. Deforestation causes global warming. 2006.

10. FAO. Integrating agriculture in national adaptation plans. 2015.

11. Asumadu-Sarkodie S, Owusu PA. The potential and economic viability of wind farms in Ghana. Energ. Source. Part A. 2016;38:695-701.

12. Asumadu-Sarkodie S, Owusu PA. The potential and economic viability of solar photovoltaic power in Ghana. Energ. Source. Part A. 2016;38:709-716.

13. FAO. Sustainable development goals. World's 2030 goals put hunger and agriculture at the centre of global policy. 2015.

14. FAO. Introduction \& status of the forestry sector in Ghana. 2016.

15. Asumadu-Sarkodie S, Owusu PA. The relationship between carbon dioxide and agriculture in Ghana: A comparison of
VECM and ARDL model. Environ. Sci. Pollut. Res. Int. 2016; 23:10968-10982.

16. UNFCCC. Ghana's second national communication to the UNFCCC. 2011.

17. Asumadu-Sarkodie S, Owusu PA. Forecasting Nigeria's energy-use by 2030, an econometric approach. Energ. Source. Part B. 2016;11:990-997.

18. Asumadu-Sarkodie S, Owusu PA. Energy use, carbon dioxide emissions, GDP, industrialization, financial development and population, a causal nexus in Sri Lanka: With a subsequent prediction of energy use using neural network. Energ. Source. Part B. 2016;11:889-899.

19. Asumadu-Sarkodie S, Owusu PA. Carbon dioxide emission, electricity consumption, industrialization and economic growth nexus: The Beninese Case. Energ. Source. Part B. 2016;11:1089-1096.

20. Asumadu-Sarkodie S, Owusu PA. The causal nexus between energy use, carbon dioxide emissions and macroeconomic variables in Ghana. Energ. Source. Part B. 2016. Available from: http://dx.doi.org/10.1080/15567249.2016.1225134.

21. Asumadu-Sarkodie S, Owusu PA. The causal effect of carbon dioxide emissions, electricity consumption, economic growth and industrialization in Sierra Leone. Energ. Source. Part $B$. 2017;12:32-39.

22. Adom PK, Bekoe W, Amuakwa-Mensah F, Mensah JT, Botchway E. Carbon dioxide emissions, economic growth, industrial structure, and technical efficiency: Empirical evidence from Ghana, Senegal, and Morocco on the causal dynamics. Energy 2012;47:314-325.

23. Asumadu-Sarkodie S, Owusu PA. The relationship between carbon dioxide emissions, electricity production and consumption in Ghana. Energ. Source. Part B. 2016. Available from: http://dx.doi.org/10.1080/15567249.2016.1227885.

24. Asumadu-Sarkodie S, Owusu PA. A multivariate analysis of carbon dioxide emissions, electricity consumption, economic growth, financial development, industrialization and urbanization in Senegal. Energ. Source. Part B. 2017;12:77-84.

25. Asumadu-Sarkodie S, Owusu PA. Multivariate co-integration analysis of the Kaya factors in Ghana. Environ. Sci. Pollut. Res. Int. 2016;23:9934-9943.

26. Asumadu-Sarkodie S, Owusu PA. Carbon dioxide emissions, GDP, energy use and population growth: A multivariate and causality analysis for Ghana, 1971-2013. Environ. Sci. Pollut. Res. Int. 2016;23:13508-13520.

27. Index Mundi. Ghana. 2016.

28. Asumadu-Sarkodie S, Owusu P. The casual nexus between child mortality rate, fertility rate, GDP, household final consumption expenditure, and food production index. Cogent Econ. \& Fin. 2016;4:1191985.

29. Pesaran MH, Shin Y. An autoregressive distributed-lag modelling approach to cointegration analysis. Econ. Soc. Monogr. 1998;31:371-413.

30. Pesaran MH, Shin Y, Smith RJ. Bounds testing approaches to the analysis of level relationships. J. Appl. Econom. 2001;16:289-326.

31. Granger CW. Some recent development in a concept of causality. J. Econometrics 1988;39:199-211. 